\title{
Новый российский кризис: снижение потребления на фоне социальной апатии
}

Н.И. Суслов, доктор экономических наук, Институт экономики и организации промышленного производства СО РАН, Новосибирск. E-mail: nsus@academ.org

Анализируются динамика и структура ВВП, доходов и расходов населения в 2009 г., 2014-2015 гг. Диагностировано, что население воспринимает текущий кризис как затяжной и переходящий в стагнацию. Удорожание и снижение объема импорта сильно воздействовали на структурные показатели и дефляторы элементов ВВП, в частности, обусловив большой разрыв в индексах цен производства, с одной стороны, а с другой - конечного использования, валового накопления и чистого экспорта. Сильный спад потребления может в определенной мере отражать пессимистические настроения домохозяйств с высокими и средними доходами. Нетипичный для краткосрочных рецессий рост прибыли сопровождается резким снижением реальной оплаты труда.

Ключевые слова: элементы ВВП, рецессия, денежные доходы и расходы населения, сбережения домашних хозяйств, сальдированный финансовый результат

\section{Импорт ушел, экспорт подешевел}

Для начала взглянем на объем и структуру ВВП в разрезе направлений его использования (элементов ВВП), для которых опубликованы не только показатели в текущих ценах, но и индексы изменения физического объема (табл. 1). Такие индексы даются конечному потреблению, валовому накоплению, а также экспорту и импорту. Соответственно, опубликованы и дефляторы указанных элементов - индексы цен.

Первое, что бросается в глаза при анализе, - большой разрыв между дефлятором ВВП в целом и дефляторами потребления домашних хозяйств и валового накопления. Незначительный общий рост уровня цен - на 7,2\% - более чем вдвое ниже индексов для потребления домашних хозяйств и валового накопления основного капитала. Может ли такое быть? Да, если вспомнить, что ВВП характеризует лишь внутреннее производство, а следовательно, его дефлятор показывает рост цен только на отечественные товары и услуги. Ключевым же генератором инфляции в 2015 г. было падение курса рубля к основным конвертируемым 
валютам и соответственно удорожание импортной продукции: как следует из представленных в таблице 1 данных - на 41\%. И домашние хозяйства, и инвесторы не отказались от импорта совсем, хотя и сократили на него спрос более чем на 1/4. Этот скачкообразно подорожавший импорт и добавил в дефляторы потребления и накопления почти по 10 п. п.

Таблица 1. Элементы, структура и динамика использования валового внутреннего продукта РФ в 2014-2015 гг.

\begin{tabular}{|c|c|c|c|c|c|c|c|}
\hline \multirow[b]{2}{*}{ Показатель } & \multicolumn{2}{|c|}{2014} & \multicolumn{3}{|c|}{2015} & \multicolumn{2}{|c|}{$\begin{array}{c}\text { Темп роста, \% } \\
\text { к предыдущему } \\
\text { году }\end{array}$} \\
\hline & $\begin{array}{l}\text { млрд } \\
\text { руб. }\end{array}$ & $\begin{array}{l}\text { струк- } \\
\text { тура, \% }\end{array}$ & $\begin{array}{l}\text { млрд } \\
\text { руб. }\end{array}$ & $\begin{array}{l}\text { струк- } \\
\text { тура, \% }\end{array}$ & $\begin{array}{c}\text { струк- } \\
\text { тура } \\
\text { в ценах } \\
2014 \text { г., } \\
\%\end{array}$ & $\begin{array}{c}\text { физи- } \\
\text { ческих } \\
\text { объемов }\end{array}$ & $\begin{array}{c}\text { уровней } \\
\text { цен } \\
\text { (дефля- } \\
\text { торы) }\end{array}$ \\
\hline Валовой внутренний продукт & 77893,1 & 100,0 & 80412,5 & 100,0 & 100,0 & 96,3 & 107,2 \\
\hline \multicolumn{8}{|l|}{ Из него: } \\
\hline $\begin{array}{l}\text { Расходы на конечное потреб- } \\
\text { ление: }\end{array}$ & 56336,4 & 72,3 & 59116,8 & 73,5 & 70,3 & 92,1 & 113,9 \\
\hline домашних хозяйств & 41435,8 & 53,2 & 43301,3 & 53,8 & 50,3 & 89,9 & 116,2 \\
\hline государственного управления & 14612,7 & 18,8 & 15482,2 & 19,3 & 19,6 & 98,2 & 107,9 \\
\hline Валовое накопление: & 16436,1 & 21,1 & 16812,8 & 20,9 & 17,7 & 81,7 & 125,2 \\
\hline основного капитала & 16651,5 & 21,4 & 17696,4 & 22,0 & 21,1 & 92,4 & 115,0 \\
\hline $\begin{array}{l}\text { изменение запасов } \\
\text { материальных оборотных } \\
\text { средств }\end{array}$ & $-215,4$ & $-0,3$ & $-883,6$ & $-1,1$ & $-2,6$ & В 9,1 раза* & 45,1 \\
\hline Чистый экспорт & 5167,8 & 6,6 & 6511,3 & 8,1 & 15,0 & 193,6 & 65,1 \\
\hline экспорт & 21464,2 & 27,6 & 23606,5 & 29,4 & 31,4 & 103,1 & 106,7 \\
\hline импорт & 16296,4 & 20,9 & 17095,2 & 21,3 & 16,4 & 74,4 & 141,0 \\
\hline Статистическое расхождение & $-47,1$ & $-0,1$ & $-2028,4$ & $-2,5$ & $-3,1$ & & \\
\hline $\begin{array}{l}\text { Изменение условий внешней } \\
\text { торговли (terms of trade) }\end{array}$ & & & & & & & 75,7 \\
\hline
\end{tabular}

Источник: расчеты автора, данные Росстата: Национальные счета. URL: http:// www.gks.ru/wps/wcm/connect/rosstat_main/rosstat/ru/statistics/accounts/ (дата обращения: 10.03.2015) .

${ }^{*}$ Сокращение.

Отдельно следует сказать о дефляторе валового накопления в целом, составившем 125,2\%, что более чем на 10 п. п. 
выше, чем по накоплению только основного капитала. На его уровне очень сильно сказалось уменьшение физического объема за счет запасов материальных оборотных средств - почти на 900 млрд руб., если мерить в текущих ценах 2015 г., или минус 1,1\% ВВП. Картина оказывается еще более впечатляющей при расчетах в постоянных ценах, что позволяет оценить изменение физического объема запасов. Показатель абсолютного сокращения их объема возрастает при этом более чем в девять раз и достигает 2 трлн руб., или минус 2,6\% в структуре ВВП, свидетельствуя о серьезном ухудшении условий ведения хозяйства и трудностях обеспечения воспроизводственного процесса. Индекс-дефлятор статьи сокращения запасов материальных оборотных средств, таким образом, составляет менее 50\%. Несомненно, это вызвано снижением объемов импорта: импортных материалов и комплектующих, которые стало невозможно закупать в прежних масштабах в условиях санкций, усилившихся ограничений по кредитованию и падения курса рубля.

Импорт в целом подорожал более чем на 40\%, а его физический объем снизился на 25,6\%, по экспорту же рост цен был практически таким же, как и в среднем по отечественным товарам и услугам, даже чуть менее - лишь 6,7\%. Вырос его физический объем, хотя и незначительно - на 3,1\%, что меньше, чем можно было ожидать при столь значительном обесценении рубля и снижении индекса условий внешней торговли, представляющего собой отношение дефлятора экспорта к дефлятору импорта и составившего 75,7\%. Данный показатель, с одной стороны, характеризует изменение прибыльности внешней торговли, в данном случае сильно упавшей, но с другой - возможности продвижения на внешних рынках, которые в текущей ситуации были ограничены санкциями, низким качеством российской продукции и, думается, недостаточной маркетинговой культурой потенциальных экспортеров.

Очень удивил показатель чистого экспорта - разницы между экспортом и импортом. Росстат не предоставляет индексов физического объема чистого экспорта, в то время как, зная индексы физического объема и дефляторы отдельно по экспорту и импорту, рассчитать их достаточно просто, что и было нами сделано. Физический объем чистого экспорта возрос почти 
вдвое - на 93,6\%: сказалось не столько увеличение экспорта, сколько уменьшение импорта. И при этом падение уровня цен чистого экспорта составило практически $1 / 3$ - результат удешевления экспорта нефти, других энергоносителей и сырьевых товаров. Если учесть, что доля чистого экспорта в постоянных ценах 2014 г. в ВВП возросла за рассматриваемый год с 6,6\% до 15,0\%, то, очевидно, это объясняет различие между дефлятором ВВП, с одной стороны, и дефляторами конечного потребления и валового накопления - с другой.

\section{Кризис - в действии. Ожидается стагнация: чем наполнить «кубышки»?}

Как и полагается в кризис, в 2015 г. произошло падение инвестиций - на 8,4\%, к которому следует добавить их уменьшение в предшествующем году еще на 1,5\%. Это нашло отражение и в системе национальных счетов: накопление основного капитала упало на 7,6\% в 2015 г. и на 0,6\% - в 2014 г. Снизилось и потребление домашних хозяйств - на 10,1\%. Именно данное обстоятельство - очень существенное сокращение потребления населения - заметно выше, чем снижение ВВП, составляет одну из особенностей текущего кризиса. Предыдущий кризис, пришедшийся в России на 2009 г., был по многим параметрам аналогичным нынешнему (табл. 2).

В 2009 г. также имел место значительный «уход» импорта, что сказалось на дефляторе для внутреннего производства в сравнении с такими же показателями для конечного потребления и валового накопления. Резко уменьшились и запасы материальных оборотных средств, и тоже, в основном, за счет импортных материалов и комплектующих, о чем говорит дефлятор запасов. Аналогичным образом, как и в 2015 г., вдвое выросла доля чистого экспорта в ВВП, измеренном в неизменных ценах.

Кризис 2009 г. в целом был острее, чем переживаемый нами сейчас: спад производства больше, а спад инвестиций и валового накопления - гораздо больше. Но если тогда потребление домашних хозяйств уменьшилось незначительно - всего лишь на 5\%, то во время текущего кризиса спад его превысил 10\% и оказался более сильным по сравнению со снижением уровня инвестиционной активности и накопления капитала. 
Таблица 2. Сравнительные характеристики кризисов экономики России 2009 г. и 2015 г.

\begin{tabular}{|c|c|c|c|c|}
\hline \multirow[b]{2}{*}{ Показатель } & \multicolumn{2}{|c|}{2009} & \multicolumn{2}{|l|}{2015} \\
\hline & $\begin{array}{l}\text { индексы } \\
\text { физи- } \\
\text { ческого } \\
\text { объема }\end{array}$ & $\begin{array}{c}\text { дефля- } \\
\text { торы }\end{array}$ & $\begin{array}{c}\text { индексы } \\
\text { физического } \\
\text { объема }\end{array}$ & $\begin{array}{r}\text { деф- } \\
\text { лято- } \\
\text { ры }\end{array}$ \\
\hline ВВП & 92,2 & 102,0 & 96,3 & 107,2 \\
\hline расходы на конечное потребление & 96,1 & 110,6 & 92,1 & 113,9 \\
\hline домашних хозяйств & 94,9 & 110,8 & 89,9 & 116,2 \\
\hline государственного управления & 99,4 & 110,3 & 98,2 & 107,9 \\
\hline Валовое накопление & 59,0 & 118,3 & 81,7 & 125,2 \\
\hline основного капитала & 85,6 & 108,4 & 92,4 & 115 \\
\hline изменение запасов материальных оборотных средств & & 71,5 & & 45,1 \\
\hline Чистый экспорт & 156,7 & 48,3 & 193,6 & 65,1 \\
\hline экспорт & 95,3 & 88,0 & 103,1 & 106,7 \\
\hline импорт & 69,6 & 125,4 & 74,4 & 141 \\
\hline $\begin{array}{l}\text { Доля изменение запасов материальных оборотных } \\
\text { средств в ВВП: } \\
\text { в текущих ценах }\end{array}$ & -3, & & $-1,1$ & \\
\hline в ценах предыдущего года & $-4,4$ & & $-2,6$ & \\
\hline $\begin{array}{l}\text { Доля чистого экспорта в ВВП: } \\
\text { в текущих ценах }\end{array}$ & 7,4 & & 8,1 & \\
\hline в ценах предыдущего года & 15 & & 15,0 & \\
\hline
\end{tabular}

Источник: данные Росстата, расчеты автора на основе данных Росстата.

Это не типично для обычных экономических кризисов, называемых также рецессиями, и может свидетельствовать о том, что общество оценивает текущее сокращение производства как затяжное, т. е. как рецессию, переходящую в стагнацию. Если ожидается, что рецессия будет недолгой, а снизившиеся доходы в скором времени восстановят свой рост, то рациональное поведение домохозяйств состоит в том, чтобы все же не сокращать потребление, финансируя разницу между доходами и расходами кредитами или используя для этого собственные накопления. После быстрого возобновления производства и доходов кредиты можно погасить и начать восстанавливать личные активы до желаемых уровней.

Напротив, если кризис ожидается затяжным, а доходы - низкими длительный период времени, то может возникнуть своего рода «социальная апатия». Может оказаться, что впоследствии взятые кредиты гасить будет не из чего. Тогда следует ожидать 
сокращения кредитов и вообще роста сбережений «на черный день». Сильно падает и потребление ${ }^{1}$. Понятно, что такая теоретическая схема в любом случае может соответствовать поведению лишь той части населения, которая реально кредитоспособна и действительно осуществляет выбор структуры своих доходов в разрезе оплаты потребления и сбережений. Это может относиться лишь к семьям с достаточно высокими доходами, которые могли добровольно пойти на сокращение объемов покупок ради увеличения средств «в кубышке».

Ожидания населения о том, что кризис примет долгосрочный характер, особенно ярко проявились в 2015 г. Так, согласно статистике Центрального банка России, объем кредитов, выданных банковским сектором физическим лицам, упал на $1 / 3$, в то время как в 2010-2013 гг. он рос средним темпом 135\% и только в 2014-м - году «вползания» в рецессию - чуть-чуть снизился. О том же говорит и динамика сбережений населения (табл. 3). На фоне сокращения покупок товаров и услуг в реальном измерении (т. е. при неизменных ценах) на 10\% реальный объем сбережений возрос на 95\%, а в текущих ценах - в 2,25 раза.

Вполне ожидаемые перемены произошли в структуре сбережений: уход из подорожавшей иностранной валюты и рост депозитов и вкладов в ценные бумаги. Причем данная статья в абсолютном значении выросла почти в девять раз, демонстрируя доверие населения к отечественной банковской системе. Статья, обозначенная в таблице 3 в разделе сбережения как «Прочие», рассчитана как разность между суммой сбережений и тремя публикуемыми Росстатом статьями их использования (вклады, приобретение валюты, изменение остатков на руках). В нее попадают как сальдо банковских кредитов, так и чистые покупки имущества, а, может быть, и еще что-нибудь, типа вкладов за рубежом, не учтенных официальной статистикой. Объем «прочих» сбережений за год вырос более чем в 40 раз, свидетельствуя о серьезных приготовлениях населения к дальнейшей

\footnotetext{
1 Такое, во многом добровольное, приспособление домохозяйств к долгосрочному падению доходов обосновывается так называемой «новой классической экономической теорией» и моделью реального бизнесцикла. В 2004 г. Ф. Кидланд и Э. Прескотт получили Нобелевскую премию за «вклад в изучение влияния фактора времени на экономическуюполитику и за исследования движущих сил деловых циклов» [1-3]
} 
рецессии, достиг почти $30 \%$ от всех сбережений - столько же, сколько пришлось на изрядно снизившиеся закупки иностранной валюты.

\section{Таблица 3. Денежные доходы, расходы} и сбережения населения РФ в 2014-2015 гг.

\begin{tabular}{|c|c|c|c|c|c|c|}
\hline \multirow{2}{*}{ Показатель } & \multicolumn{2}{|c|}{2014} & \multicolumn{2}{|c|}{2015} & \multicolumn{2}{|c|}{$\begin{array}{c}\text { Темп роста, \% } \\
\text { к предыдущему } \\
\text { году }\end{array}$} \\
\hline & $\begin{array}{c}\text { объем, } \\
\text { млрд руб. }\end{array}$ & $\begin{array}{c}\text { струк- } \\
\text { тура, } \\
\%\end{array}$ & $\begin{array}{c}\text { объем, } \\
\text { млрд руб. }\end{array}$ & $\begin{array}{l}\text { струк- } \\
\text { тура, \% }\end{array}$ & $\begin{array}{c}\text { в } \\
\text { текущих } \\
\text { ценах }\end{array}$ & $\begin{array}{c}\text { в посто- } \\
\text { янных } \\
\text { ценах }\end{array}$ \\
\hline \multicolumn{7}{|c|}{ Денежные доходы населения } \\
\hline От предпринимательства & 4055,4 & 8,4 & 3883,8 & 7,3 & 95,8 & 82,9 \\
\hline Оплата труда & 31767,2 & 65,8 & 35113,9 & 66,0 & 110,5 & 95,7 \\
\hline Социальные выплаты & 8690,1 & 18,0 & 9629,7 & 18,1 & 110,8 & 95,9 \\
\hline От собственности & 2800,2 & 5,8 & 3511,4 & 6,6 & 125,4 & 108,6 \\
\hline Другие & 965,6 & 2,0 & 1064,1 & 2,0 & 110,2 & 95,4 \\
\hline Всего & 48278,5 & 100,0 & 53202,9 & 100,0 & 110,2 & 95,4 \\
\hline \multicolumn{7}{|c|}{ Денежные расходы населения } \\
\hline Товары и услуги & 36353,7 & 76,0 & 37933,7 & 70,7 & 104,3 & 90,3 \\
\hline $\begin{array}{l}\text { Обязательные платежи } \\
\text { и взносы }\end{array}$ & 5696,9 & 11,9 & 5958,7 & 11,1 & 104,6 & 90,6 \\
\hline Сбережения & 3331,2 & 7,0 & 7501,6 & 14,0 & 225,2 & 195,0 \\
\hline Другие & 2461,5 & 5,1 & 2226,9 & 4,2 & 90,5 & 78,3 \\
\hline Всего & 47843,3 & 100,0 & 53620,9 & 100,0 & 112,1 & 97,0 \\
\hline \multicolumn{7}{|c|}{ Сбережения } \\
\hline Вклады и ценные бумаги & 386,2 & 11,6 & 3458,2 & 46,1 & 895,4 & 775,2 \\
\hline Валюта & 2800,2 & 84,1 & 2234,5 & 29,8 & 79,8 & 69,1 \\
\hline Остатки на руках & 96,6 & 2,9 & $-425,6$ & $-5,7$ & $-440,8$ & $-381,6$ \\
\hline Прочие & 48,3 & 1,4 & 2234,5 & 29,8 & 4628,4 & 4007,3 \\
\hline Всего & 3331,2 & 100,0 & 7501,6 & 100,0 & 225,2 & 195,0 \\
\hline
\end{tabular}

Источники: расчеты автора на основе данных: Социально-экономическое положение России. 2015 год (СЭП РФ 2015). Федеральная служба государственной статистики (Росстат) . - М., 2016. - С. 202-220.

В структуре денежных доходов населения изменения были не столь существенны, но все же отметим снижение значения 
предпринимательских доходов и рост доходов от собственности. Первое обстоятельство очевидно, оно объясняется ухудшением условий ведения бизнеса, вызванным ростом ставок по кредитам, недоступностью их для индивидуальных предпринимателей и малого бизнеса, усилением давления на бизнес в условиях сокращения доходной части бюджета, а также общим снижением спроса. По-видимому, значительная часть официально зарегистрированных предпринимателей либо снизили деловую активность, либо прекратили ее совсем. Возможно также, что за цифрами уменьшения доли предпринимательских доходов в их общей структуре на $14 \%$ стоят уход в тень и их сокрытие. Рост значимости доходов от собственности весьма вероятно объясняется увеличением выплат дивидендов в крупных компаниях, профинансированным возросшей прибылью.

Справедливости ради следует сказать, что рост сбережений, сокращение кредитов населению, уход его из валютных активов и увеличение доли в сбережениях статьи «Прочие» имело место и в 2009 г., а значит, и тогда пессимистические настроения относительно длительности рецессии в определенной степени присутствовали среди населения. Однако, судя по косвенным данным (статистика по кредитам населению имеется лишь с апреля 2009 г.), уменьшение кредитования населения не было тогда столь сильным, как в 2015 г. Главное же отличие, позволяющее судить, что общество воспринимает текущий кризис как более затяжной, - резкое падение потребления.

\section{Прибыль выросла - нетипично для рецессий}

Другое отличие данной рецессии от предыдущей состоит в динамике прибыли, или публикуемого Росстатом «Сальдированного финансового результата» ${ }^{2}$. В 2009 г. его объем сократился по отношению к предыдущему году более чем на $20 \%$, а в 2015 г. - вырос почти на 50\% (табл. 4). При этом по многим видам деятельности рост составил разы: в производстве нефтепродуктов и металлургическом - в 2,5 раза, в финансовой деятельности - в 9,2 раза, а в химическом производстве - даже в 15,5 paza.

\footnotetext{
${ }^{2}$ Рассчитан для организаций без субъектов малого предпринимательства, банков, страховых организаций и бюджетных учреждений.
} 
Таблица 4. Элементы, структура и динамика валового внутреннего продукта по источникам формирования в 2014-2015 гг.

\begin{tabular}{|l|c|c|c|c|c|c|}
\hline \multirow{2}{*}{\multicolumn{1}{|c|}{ Показатель }} & \multicolumn{2}{|c|}{2014} & \multicolumn{2}{c|}{2015} & \multicolumn{2}{c|}{ Темп роста, \% } \\
\cline { 2 - 7 } & $\begin{array}{c}\text { объем, } \\
\text { мдрд руб. }\end{array}$ & $\begin{array}{c}\text { струк- } \\
\text { тура, \% }\end{array}$ & $\begin{array}{c}\text { объем, } \\
\text { мдрд руб. }\end{array}$ & $\begin{array}{c}\text { струк- } \\
\text { тура, \% }\end{array}$ & $\begin{array}{c}\text { в } \\
\text { текущих } \\
\text { ценах }\end{array}$ & $\begin{array}{c}\text { в посто- } \\
\text { янных } \\
\text { ценах }\end{array}$ \\
\hline Добавленная стоимость & 67600,9 & 100 & 72371,0 & 100 & 107,1 & \\
\hline Оплата труда наемных работников & 34894,4 & 51,6 & 36547,4 & 50,5 & 104,7 & 90,6 \\
\hline $\begin{array}{l}\text { Валовая прибыль экономики и вало- } \\
\text { вые смешанные доходы }\end{array}$ & 31992,1 & 47,3 & 35045,6 & 48,4 & 109,5 & 94,8 \\
\hline $\begin{array}{l}\text { В том числе сальдированный } \\
\text { финансовый результат }\end{array}$ & $\mathbf{6 0 7 8 , 9 *}$ & $\mathbf{9 , 0}$ & $\mathbf{9 0 9 4 , 6 *}$ & $\mathbf{1 2 , 6}$ & $\mathbf{1 4 9 , 6}$ & 129,5 \\
\hline Налоги на производство & $-714,4$ & $-1,1$ & $-777,9$ & $-1,1$ & 108,9 & 94,3 \\
\hline
\end{tabular}

Источник: расчеты автора на основе данных Росстата.

*Оценка автора на основе данных СЭП РФ 2014-2015 гг. (за 11 месяцев).

** «Другие налоги на производство» - рассчитано как разница между объемами чистых налогов на производство и импорт и чистых налогов на продукты.

На первый взгляд, такие цифры роста прибыли вызывают большие сомнения в их достоверности. Но проблема достоверности статистических показателей стояла всегда, и мы не видим особых причин, почему бы данные за 2015 г. в меньшей степени отражали экономические реалии, чем за другие годы, разве что они еще носят предварительный характер и могут быть скорректированы статистическими органами в ходе дальнейшего сбора и анализа данных. Думается, в основном им можно доверять уже сейчас, поскольку методология их подготовки Росстатом отработана, а практика сложилась. Опубликованный Росстатом показатель «Рентабельности проданных товаров, продукции, работ, услуг» за 2014 г. составил 7,2\%. Он рассчитан не для всей экономики России, но примерно по тому же кругу организаций, что и сальдированный финансовый результат, рост которого в 2015 г. на 50\% означает, что в данный период времени рентабельность повысилась до 10-10,5\%, т. е до уровня 2009-2010 гг., что представляется вполне возможным на фоне ускорившейся инфляции. Что касается кратного увеличения прибыли по некоторым видам деятельности, то это вполне объяснимо низкой базой расчета: 2014 г. оказался периодом минимальных уровней рентабельности за последние 18 лет, т. е. начиная с 1998 г. 
Что может объяснить такой нетипичный для кризисов рост прибыли в экономике? Как нам кажется, ответ становится очевидным в контексте анализа соотношения динамики показателей валовой добавленной стоимости и оплаты труда (см. табл. 4). Таблица построена на основе данных о производстве ВВП по видам деятельности и по источникам дохода. ВВП отличается от валовой добавленной стоимости на величину чистых налогов на продукты. Что касается показателей оплаты труда и валовой прибыли, то они, также не включая чистых налогов на продукты, включают, однако, так называемые «Другие налоги на производство» ${ }^{3}$. Таким образом, сумма оплаты труда и валовой прибыли незначительно - в районе 1 п. п. ВВП - превышает валовую добавленную стоимость, что, конечно, не мешает анализу. Из таблицы 4 ясно видно, что прибыль в экономике возросла как следствие недостаточного роста оплаты труда, доля которой в валовой добавленной стоимости снизилась более чем на 1 п. П. Это и привело к падению реальной оплаты труда почти на 10\%, что находится в соответствии с несколько более сильным сокращением потребления - на фоне возросшей доли сбережений в доходах.

Выше мы высказывали предположение, что сокращение потребления может быть связано с некоей социальной апатией и носило в определенной степени добровольный характер в ожидании затяжного сокращения доходов, как это теоретически следует из модели реального бизнес-цикла, разработанной школой «новых классиков». Но, с другой стороны, оно было, конечно, усилено отставанием повышения оплаты труда от роста выручки и инфляции, что в условиях падения курса рубля - говоря на языке марксистской политической экономии - называется увеличением «нормы эксплуатации рабочей силы». И здесь уже можно сетовать на слабость социального блока правительства, профсоюзов, а также неразвитость гражданского общества, до сих пор не создавшего серьезных институтов отстаивания

\footnotetext{
3 «Другие налоги на производство - это налоги, связанные с использованием факторов производства (труда, земли, капитала), а также платежи за лицензии и разрешение заниматься какой-либо деятельностью или другие обязательные платежи, уплата которых необходима для деятельности производящей единицы-резидента» (Методологические пояснения к разделу сайта Росстата «Национальные счета». URL: http:// www.gks.ru/free_doc/new_site/vvp/metod.htm).
} 
интересов людей. Думается, что социальная поддержка и меры, направленные на сдерживание чересчур сильного роста прибыли за счет оплаты труда, смягчили бы падение потребления и позволили бы увеличить сберегательные активы.

\section{Статистика доходов и оплаты труда: есть проблемы с пониманием}

В заключение мы хотели бы прокомментировать различия в динамике публикуемых Росстатом показателей оплаты труда, что может породить сомнения в их достаточной достоверности. В таблице 5 представлены три таких показателя - по начисленной заработной плате, оплате труда по данным о денежных доходах и оплате труда по данным СНС. Два первых показателя публикуются в ежемесячном докладе «Социально-экономическое положение России», а третий - в разделах официальных изданий Росстата «Национальные счета».

Таблица 5. Сравнение различных данных по оплате труда работников организаций РФ в 2014-2015 гг.

\begin{tabular}{|c|c|c|c|c|c|c|}
\hline \multirow[b]{2}{*}{ Показатель } & \multicolumn{2}{|c|}{2014} & \multicolumn{2}{|c|}{2015} & \multirow{2}{*}{$\begin{array}{l}\text { Темп } \\
\text { в те- } \\
\text { кущих } \\
\text { ценах }\end{array}$} & \multirow[b]{2}{*}{\begin{tabular}{|c} 
Темп \\
в ценах \\
2014 г.
\end{tabular}} \\
\hline & $\begin{array}{c}\text { объем, } \\
\text { млрд руб. }\end{array}$ & $\begin{array}{c}\text { доля } \\
\text { к дан- } \\
\text { ным } \\
\text { СНС, \% }\end{array}$ & $\begin{array}{c}\text { объем, } \\
\text { млрд } \\
\text { руб. }\end{array}$ & $\begin{array}{c}\text { доля } \\
\text { к данным } \\
\text { СНС, \% }\end{array}$ & & \\
\hline $\begin{array}{l}\text { Начисленная зарплата в годовом } \\
\text { измерении }\end{array}$ & 27895,9 & 79,9 & 29123,4 & 79,7 & 104,4 & 90,4 \\
\hline $\begin{array}{l}\text { Оплата труда по данным о структуре } \\
\text { денежных доходов }\end{array}$ & 31767,2 & 91,0 & 35113,9 & 96,1 & 110,5 & 95,7 \\
\hline Оплата труда по данным СНC & 34894,4 & 100,0 & 36547,4 & 100,0 & 104,7 & 90,7 \\
\hline
\end{tabular}

Источник: расчеты автора на основе данных Росстата.

Как видно, динамика второго показателя несколько отличается от первого и третьего. Наиболее полный показатель - из «Национальных счетов», он включает не только денежные выплаты, но и лишь начисляемые страховые и пенсионные выплаты, поступающие непосредственно в соответствующие фонды, минуя карманы наемных работников. Кроме того, туда включены смешанные доходы, создаваемые в домашних хозяйствах, а также оцениваемая статистикой скрытая оплата труда. 
Оплата труда по данным о структуре денежных доходов определена не слишком точно. Основу составляет начисленная оплата труда, но к ней также добавляется скрытая заработная плата. Очевидно, в этом агрегате не присутствуют смешанные доходы, а также вознаграждение в неденежной форме, которые входят в показатель из «Национальных счетов». В любом случае мы затрудняемся объяснить, почему показатель оплаты труда, определяемой по доле денежных доходов, в 2015 г. столь сильно сократил «дистанцию» от показателя «Национальных счетов». Это что же - монетизация неденежных доходов?

В своем анализе изменения пропорций доходов и направлений использования ВВП мы взяли поэтому за основу показатели «Национальных счетов», находящихся в большем взаимном соответствии. Индикаторы денежных доходов и расходов населения использованы нами для анализа изменений в их структуре, также проливающих свет на особенности поведения людей во время кризисов.

\section{Литература}

1. Long John B., Jr., Plosser Charles. Real Business Cycles // Journal of Political Economy. - 1983. - 91 (1): 39-69. doi:10.1086/261128. 2. Plosser Charles I. Understanding real business cycles // Journal of Economic Perspectives. - 1989. - 3: 51-77. doi:10.1257/jep.3.3.51. 3. Romer David. Real-Business-Cycle Theory // Advanced Macroeconomics (Fourth ed.). - New York: McGraw-Hill, 2011. - P. 189-237. ISBN 978-0-07-351137-5. 